\title{
Testis Mesothelioma: A Case Report
}

\author{
Mehmet Kucukoner, ${ }^{\mathrm{a}, \mathrm{e}}$, Firat Ugur ${ }^{\mathrm{b}}$, Inal Ali ${ }^{\mathrm{a}}$, \\ Kaplan Muhammed Alia, Bozkurt Yasarc, \\ Atar Murat ${ }^{c}$, Isikdogan Abdurrahman ${ }^{\mathrm{a}}$, Zuhat Urakci ${ }^{\mathrm{d}}$
}

\begin{abstract}
Malignant mesothelioma (MM) of the tunica vaginalis testis is uncommon but often fatal malignancy. Radical orchiectomy should be primary therapy. Moreover, in some cases adjuvant chemotherapy or radiotherapy is given. We report a case of localized MM of the who primarily referred to the hospital with a left testis mass. The aim of this study is to evaluate the etiology, the diagnosis and the prognosis of the testis MM in term of our case.
\end{abstract}

Keywords: Testis; Mesothelioma

\section{Introduction}

Mesothelioma originates from the mesothelial cells in the serous membrane, such as the pleura, peritoneum, and tunica vaginalis of testis. Testicular mesothelioma develops in the serous membranous lining that surrounds the testicle, the tunica vaginalis. Testicular mesotheliomas comprise from $1 \%$ to $5 \%$ of all cases of mesothelioma [1]. A mesothelioma of the tunica vaginalis of the paratesticular region is unusual but often fatal malignancy of the male genitalia. Previous exposure to asbestos or asbestos-containing materials should take into consideration a important risk factor for the develop-

Manuscript accepted for publication June 12, 2012

${ }^{a}$ Medical Oncology Department, Dicle University Medicine Faculty, Diyarbakir, Turkey

${ }^{\mathrm{b}}$ Pathology Department, Dicle University Medicine Faculty, Diyarbakir, Turkey

${ }^{\mathrm{c}}$ Urology Department, Dicle University Medicine Faculty, Diyarbakir, Turkey

${ }^{\mathrm{d} O n c o l o g y}$ Department, Dicle University Medicine Faculty, Turkey

${ }^{\mathrm{e}}$ Corresponding author: Mehmet Kucukoner.

Email:drmehmetonko@hotmail.com

doi:10.4021/wjnu19w ment of malignant mesothelioma. In addition, the trauma and hydrocele are risk factors [2]. These tumors were frequently seen in the patients with old ages [3]. Despite aggressive surgical and systemic therapy the prognosis generally is poor. Rarely, long-term survivals can be seen. Radiotherapy is accepted as more effective than chemotherapy. Radical surgery plus adjuvant radiotherapy is observed to provide the best results [4].

We present a testis mesothelioma case, so far, with good prognosis, and unknown etiology which treated with surgery and radioheraphy.

\section{Case Report}

A 68-year-old male presented to our outpatient department with painful, palpable mass in his left testis that was gradually progressive for 2 months. On the physical examination a hard palpable mass of size $5 \times 4 \mathrm{~cm}$ mass $\mathrm{cm}$ was detected in the a testicular enlargement on the left hemiscrotum and lymph nodes were not in the inguinal region. The scrotum was normal except for an apparent enlarged. He had no history of previous surgery or trauma to the testis. The patient is unknown any exposure to asbestos in the past. The laboratory examinations was normal in complete blood count and renal and liver functions. Alpha fetoprotein was $3.07 \mathrm{ng} /$ $\mathrm{mL}$ (normal $<20 \mathrm{ng} / \mathrm{mL}$ ) and the beta human chorionic gonadotropin level was $1.20 \mathrm{mIU} / \mathrm{mL}$ (normal $<5 \mathrm{mIU} / \mathrm{mL}$ ). In the ultrasound examination it was observed that the left testis was enlarged $5 \mathrm{cms}$ showing diffusely heterogenous echo-texture and irregular nodular surface with irregular hypoechoic thickening of the scrotal. Computed tomography performing for staging showed a nodular mass in left testis and he had not distatnt metastasis. The patient was undergone left radical orchiectomy for treatment and diagnosis aims. Macroscopically, the left orchiectomized specimen, 4 x $5 \mathrm{~cm}$ in size, was composed of the testis with a paratesticular tumor mass arising from the tunica vaginalis. Microscopically, in the testicular tissue, uniform cuboidal shaped atypical cells showed parenchimal infiltration (Fig. 1) and strong positivity with mesothelin (Fig. 2) that suggestive of the diagnosis of epithelial mesothelioma. With all of these 


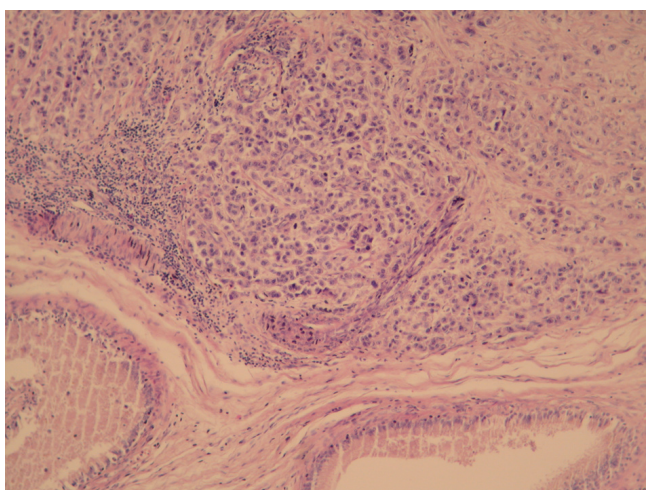

Figure 1. Uniform cuboidal shaped atypical tumoral cells infiltrating the testis tissue ( $\mathrm{H}$ and $\mathrm{E}$ stain, $\mathrm{x} 100)$.

findings, localizated stage Malign Mesothelioma of testis was diagnosed to the patient. The patient was managed radiotherapy to prevent from recurrence. The patient is alive for two years without recurrence.

\section{Discussion}

Mesothelial lesions involving the paratesticular region include mesothelial cysts, reactive mesothelial hyperplasia, adenomatoid tumors, benign cystic mesothelioma, well-differentiated papillary mesothelioma, and malignant mesothelioma [5]. Testicular mesotheliomas are usually malignant and aggressive tumors that are morphologically identical to mesotheliomas at other sites, and may therefore show an epithelial, spindle cell or biphasic morphology [6]. Although trauma and long term hydrocele have been considered as the predisposing factors for development of malignant mesothelioma, the only well established risk factor is asbestos exposure $[2,7]$. Symptoms have been confined to the appearance of testicular lumps, swelling of the scrotum and rarely hydrocele.

Mesotheliomas are difficult to manage and no clear guidelines exist for management. Surgery has been suggested and orchidectomy is generally performed. However, the treatment of testis germ tumors is easy and these tumors are very well prognosis. A review showed a median survival of 23 months for mesotheliomas of tunica vaginalis. Recurrence occurred in $52.5 \%$ of the cases. In some cases of disseminated mesothelioma, adjuvant chemotherapy or radiotherapy was given. Although reports on adjuvant treatments were limited, radiotherapy appeared to be more effective than chemotherapy [3].

Only 76 cases of testicular malignant mesothelioma have been reported in the English literature until 2001. Previous exposure to asbestos is reported in $40 \%$ of the patients. In $75 \%$ of the cases microscopic examination reveals epithelial, papillary mesothelioma [8]. Two cases were reported in our

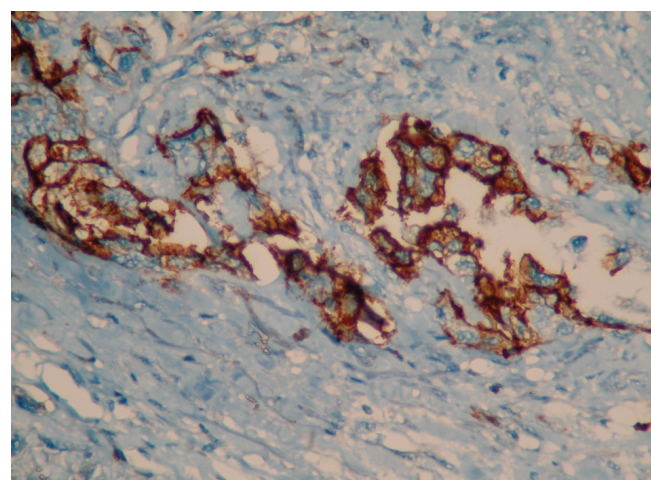

Figure 2. Strong mesothelin positivity in the tumoral cells (Immunoperoxidase, $x$ 400).

country so far [7, 9]. Absence of risk factors in our presenting case is interesting and not aggressive for two years. The histhopathology of our case was epithelial type.

Consequently, the malignant mesothelioma of the tunica vaginalis of the testis is rare tumors. However, it should be considered whenever a paratesticular mass lesion is seen even without a history of trauma or asbestos exposure.

\section{Conflict of Interest}

There is no conflict of interest between writers.

\section{References}

1. Shimada S, Ono K, Suzuki Y, Mori N. Malignant mesothelioma of the tunica vaginalis testis: a case with a predominant sarcomatous component. Pathol Int. 2004;54(12):930-934.

2. Jones MA, Young RH, Scully RE. Malignant mesothelioma of the tunica vaginalis. A clinicopathologic analysis of 11 cases with review of the literature. Am J Surg Pathol. 1995;19(7):815-825.

3. Plas E, Riedl CR, Pfluger H. Malignant mesothelioma of the tunica vaginalis testis: review of the literature and assessment of prognostic parameters. Cancer. 1998;83(12):2437-2446.

4. Chen JL, Hsu YH. Malignant mesothelioma of the tunica vaginalis testis: a case report and literature review. Kaohsiung J Med Sci. 2009;25(2):77-81.

5. Perez-Ordonez B, Srigley JR. Mesothelial lesions of the paratesticular region. Semin Diagn Pathol. 2000;17(4):294-306.

6. Attanoos RL, Gibbs AR. Primary malignant gonadal mesotheliomas and asbestos. Histopathology. 2000;37(2):150-159.

7. Gurdal M, Erol A. Malignant mesothelioma of tunica 
vaginalis testis associated with long-lasting hydrocele: could hydrocele be an etiological factor? Int Urol Nephrol. 2001;32(4):687-689.

8. Katia R.M, William C. Nahas, Luis H. Camara-Lopes. Malignant Mesothelioma of the Tunica Vaginalis. Bra- zilian Journal of Urology.2002; 28 (2): 135-137.

9. Guney N, Basaran M, Karayigit E, Muslumanoglu A, Guney S, Kilicaslan I, Gulbarut S. Malignant mesothelioma of the tunica vaginalis testis: a case report and review of the literature. Med Oncol. 2007;24(4):449-452. 